\title{
Thermodynamic study of the separation of racemic ibuprofen by chiral liquid chromatography
}

\author{
W. M. Ferrari ${ }^{1}$; M. A. Cremasco ${ }^{1}$ \\ 1- Chemical Engineering School - University of Campinas (UNICAMP) \\ Albert Einstein Avenue, 500 - Zip code: 13083-852 - Campinas - SP - Brazil \\ Phone: (19) 3521-3931 - Fax: (19) 3521-3922 - Email: wmcferrari@ gmail.com
}

ABSTRACT: The chiral drug (RS)-2-(4-(2-methylpropyl)phenyl) propanoic acid, known as ibuprofen, is an important non-steroidal anti-inflammatory drug, also notorious for its analgesic and antipyretic properties. This medicine is market in racemic form R-(-)-ibuprofen and S-(+)-ibuprofen, however, in some countries only the second enantiomer is applied. This paper refers to the study of the thermodynamic parameters relative for separation of the racemic mixture in analytical chiral chromatographic columns packed with cellulose tris (3,5-dimethylphenylcarbamate). In this analysis, the enthalpy $\left(\Delta H^{0}\right)$, entropy $\left(\Delta S^{0}\right)$, enthalpy difference $\left(\Delta \Delta H^{0}\right)$, entropy difference $\left(\Delta \Delta S^{0}\right)$, and isoenantioselective temperature $\left(T_{i s o}\right)$ was determined by van't Hoff approach.

KEYWORDS: ibuprofen, thermodynamic parameters, chiral separation, adsorption and HPLC

\section{INTRODUCTION}

Ibuprofen was commercially introduced as a non-steroidal anti-inflammatory drug (NSAID) in the United Kingdom in 1969, and in the United States in 1974. This drug replaced others NSAIDs that caused gastrointestinal irritation and severe intolerance in the body (Palma et al., 2009). The Figure 1 shows the ibuprofen chiral structure (Chen et al., 1991).

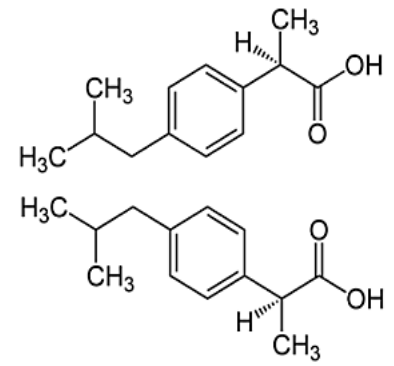

Figure 1 - Ibuprofen molecular structure: (A) R-(-)-ibuprofen; (B) S-(+)-ibuprofen. 
Many countries administer the racemic structure instead of S-(+)-ibuprofen, except some places like Switzerland and Austria (Valderrama and Poppi, 2011). The S-(+)-ibuprofen is a prostaglandin and thromboxane inhibitor. This enantiomer demonstrates better clinical efficiency, less variability in therapeutic effects and toxicity, if compared with this racemic form. In addition, it is possible to reduce the amount of drug used. R-(-)-ibuprofen structure does not display pharmacological action. Moreover, it triggers a chiral inversion on human body causing toxicity by the formation of hybrid triglycerides (Yoon et al., 2008).

High performance liquid chromatography (HPLC) can be used to obtain R-(-)-ibuprofen and $\mathrm{S}-(+)$-ibuprofen in their pure forms, when the system has a suitable device chiral recognition. In this technique, the differential migration of compounds through the chromatographic column promotes the resolution. Separations involving chiral compound in this method must employ a chiral selector on mobile phase or in the stationary phase to promote different energies in the adsorption between the analytes and the stationary phase. These energies are originated from the formation of diastereoisomeric molecules that they are spatially oriented due the intermolecular bonds, which attractive and repulsive forces are associated. Chiral recognition proposes that one enantiomer makes three simultaneous bonding with three different active site of chiral selector in which it happens a bonding of stereochemical feature, while the other enantiomer does not interact as a stereochemical (Lämmerhofer, 2010).

The analysis of thermodynamic parameters enables better understanding of the driving forces that guide this separation phenomenon (Lämmerhofer, 2010), and it also checks whether if chemisorption or physisorption occurs (Schulte and Epping, 2005). Furthermore, the study of both enthalpy and entropy changes can help in getting nonlinear isotherm parameters as demonstrated in Asnin et al. (2006).

This work aims to determine the thermodynamic parameters enthalpy, entropy, enthalpy difference, entropy difference, and isoenantioselective temperature, in analytical scale to provide information about ibuprofen separation by chiral liquid chromatography. The parameters chromatographic are determined by van't Hoff approach.

\section{MATERIALS AND METHODS}

\subsection{Setting of separation and materials}

Ferrari and Cremasco (2014) used high performance liquid chromatography to separate the racemic ibuprofen. In this separation, they employed a column packed with silica coated for the cellulose tris(3,5-dimethylphenylcarbamate). The mobile phase was composed for hexane and isopropyl alcohol in the ratio 99/1 and an additive, the trifluoroacetic acid (TFA). The authors observed that the R-(-)-ibuprofen is the most retained compound and that the S$(+)$-ibuprofen is the less retained one.

The experiments were performed in HPLC equipment, that consists of controller (CBM-20A), UV-vis detector (SPD-20A), and pump (LC-20AT), originally purchased from Shimadzu (Japan). The column and mobile phase were temperature-controlled using Quimis circulation water bath, model Q-214m2 (Brazil).

The column Lux Cellulose-1 (250 x $4.6 \mathrm{~mm})$, purchased from Phenomenex, was employed as stationary phase. Solvents hexane and isopropyl alcohol, both of HPLC grade 
(TEDIA ${ }^{\circledR}$, USA), were employed in mobile phase ratio 99/1. The additive reagent trifluoroacetic acid was used in $0.1 \%$ proportion at total volume of the mobile phase. The racemic ibuprofen and inert compound 1,3,5-tri-tert-butylbenzene (TTBB) were acquired from Sigma-Aldrich (USA). The system was operated at a flow rate of $1 \mathrm{ml} / \mathrm{min}$ and monitored at wavelength of $220 \mathrm{~nm}$. Samples of ibuprofen $(0.5 \mathrm{~g} / \mathrm{L})$ diluted in the mobile phase were injected at different temperatures to determine the retention factors.

\subsection{Methods}

To determine the thermodynamic parameters, it was adopted the chromatographic van't Hoff approach (Coym, 2010; Lämmerhofer, 2010; Nascimento et al., 2012; Oliveira and Cremasco, 2013). In this method, the retention factor $\left(k=t_{R}^{\prime} / t_{0}\right.$, with $\left.t_{R}^{\prime}=t_{R}-t_{0}\right)$ is correlated with temperature $(T)$ to provide a linear relationship, where $\Delta H^{0}$ and $\Delta S^{0}$ can be obtained by slope and intercept from

$$
\ell n(k)=-\frac{\Delta H^{0}}{R T}+\frac{\Delta S^{0}}{R}+\ln (\phi)
$$

with

$$
\phi=\frac{1-\varepsilon}{\varepsilon}
$$

Parameter $\phi$ represents the volume phase ratio between stationary and mobile phases (Jandera et al., 1982; Mihlbachler et al., 2002; Lämmerhofer, 2010). The total porosity ( $\varepsilon$ ) was determined by first moment method (Schneider and Smith, 1968; Cremasco et al., 2001).

$$
t_{R}^{\prime}=\frac{L}{v} \varepsilon
$$

Equation 4 was used to determine the energy variation between the more and less retained compound, where a linear relationship between selectivity $\left(\alpha=k_{j} / k_{i}\right)$ and temperature (T) is set (Lämmerhofer, 2010; Moreira et al., 2013).

$$
\ln (\alpha)=-\frac{\Delta \Delta H^{0}}{R T}+\frac{\Delta \Delta S^{0}}{R}
$$

Another important parameter is the isoenantioselective temperature $\left(T_{i s o}\right)$, also called isoeluotropic temperature. This temperature is that one which the chromatographic separation does not occur $(\alpha=1)$. Applying this condition in Equation 4, it is possible to obtain.

$$
T_{i s o}=\frac{\Delta \Delta H^{0}}{\Delta \Delta S^{0}}
$$




\section{RESULTS AND DISCUSSION}

\subsection{Total porosity and phase ratio}

The total porosity is an important parameter to determine isothermal adsorption and ratio phases. Total porosity was calculated by first moment method (Equation 3), where the graph of first moment of an unretained band profile method is shown in Figure 2. In this method, the inert compound TTBB is employed in chiral column and rate flow was changed from 0.2 up to $1.6 \mathrm{ml} / \mathrm{min}$ with step $0.2 \mathrm{ml} / \mathrm{min}$.

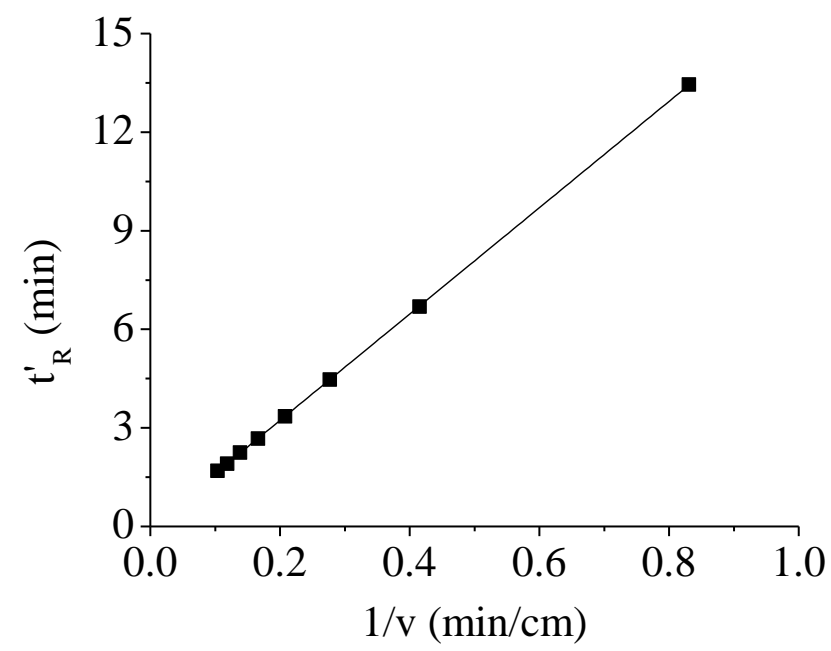

Figure 2 - Total porosity by first moment method.

The slope presented in Figure 2 provides the value of 0.647 for total porosity. The coefficient of determination was 0.999. The phase ratio, from Equation 2, is equal 0.545 . Mihlbachler et al. (2002) found the value of 0.543 for a Chiralpak AD column, $20 \mu \mathrm{m}$ particle-silica-based packing materials, coated with amylose tri (3,5-dimethylphenylcarbamate).

\subsection{Thermodynamic parameters}

Thermodynamic parameters were investigated using a variation of the van't Hoff's method, where data $\ln (k)$ vs. $T^{-1}$ were linearized according to Equation 1, as shown in Figure 3 . The temperatures chosen for this study were $15,20,25,30$, and $35^{\circ} \mathrm{C}$. This figure provides information about enthalpy difference for adsorption of the overall process $\left(\Delta H^{0}\right)$, while the intercept represents an entropy difference $\left(\Delta S^{0}\right)$. Table 1 shows the results from van't Hoff analysis. 


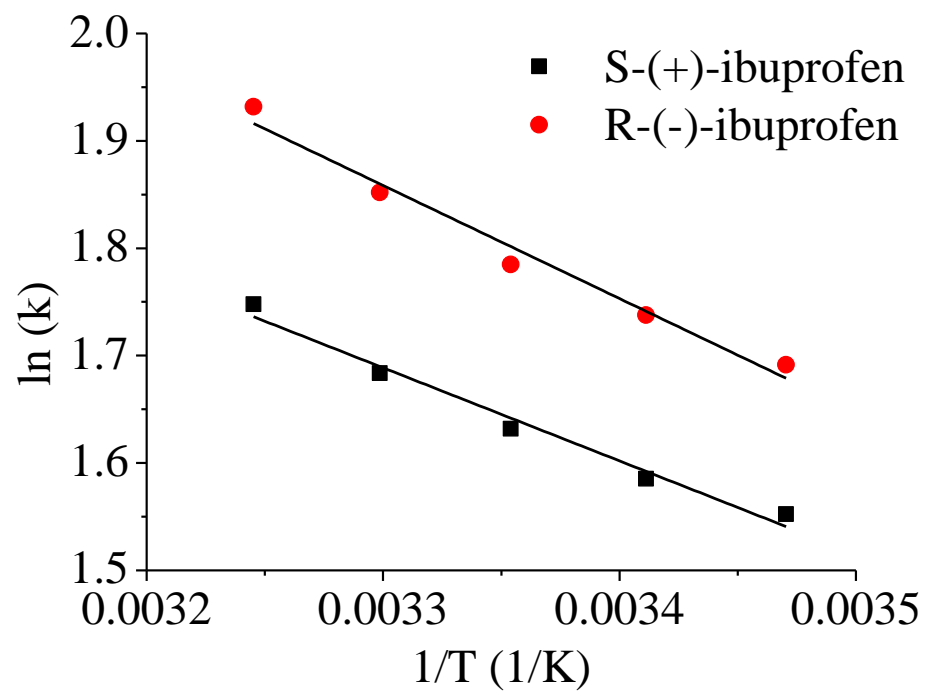

Figure 3 - Van't Hoff graphical in function of retention factor and temperature.

Table 1 - Thermodynamic parameters of the separation of racemic ibuprofen from Figure 3.

\begin{tabular}{cccc}
\hline Compound & $\Delta H^{0}(\mathrm{~J} / \mathrm{mol})$ & $\Delta S^{0}(\mathrm{~J} / \mathrm{K} \mathrm{mol})$ & $\mathrm{R}^{2}$ \\
\hline S-(+)-ibuprofen & 7212.01 & 42.89 & 0.981 \\
\hline R-(-)-ibuprofen & 8758.95 & 49.40 & 0.979
\end{tabular}

According to Schulte and Epping (2005), the values of positive $\Delta H^{0}$ suggest endothermic adsorption and values of $\Delta H^{0}$ lower than $50000 \mathrm{~J} / \mathrm{mol}$ characterize physical adsorption. The compound more retained, R-(-)-ibuprofen, binds more strongly in chiral stationary phase (CSP) since it has the largest value of enthalpy. Lämmerhofer (2010) affirms that in most instances van't Hoff plots reveal linear relationships $\left(\Delta H^{0}\right.$ invariant with $\left.\mathrm{T}\right)$ with a strong preference for exothermic adsorption processes as it can be inferred from a negative sign of the derived $\Delta H^{0}$ values, a situation that usually becomes evident in a decrease in retention with increasing temperature, what did not happened in this study. About the entropy, both enantiomers must be solvated identically in the mobile phase, and release the same number of solvent molecules when they are associated with the CSP. The S-(+)-ibuprofen has smaller values for $\Delta S^{0}$ what indicates it may have fewer degrees of freedom on the CSP (it is held at more points or it is less able to move or rotate) (Péter et al., 1998).

To better describe the separation thermodynamically, it was used a second approach in which Van't Hoff was plotted $\ln (\alpha)$ vs. $T^{-1}$ from Equation 4 as indicated in Figure 4. Data results and the isoenantioselective temperature (Figure 4) were summarized in the Table 2. This table presents the values of $\Delta \Delta H^{0}$ and $\Delta \Delta S^{0} . T_{\text {iso }}$ found was below temperature used in study. This justifies the increasing selectivity with increasing temperature. If the separation occurs below $T_{i s o}$, it could have happened a reversing in the order of compounds elution. Another important factor is that the entropic energy have more influence than enthalpy on the Gibbs energy in the temperature range studied $\left(\left|T \Delta \Delta S^{0}\right|>\left|\Delta \Delta H^{0}\right|\right.$ as observed by Lämmerhofer (2010). Higher temperatures favor the separation; however, the maximum temperature supported by the CSP is $313.15 \mathrm{~K}$. 


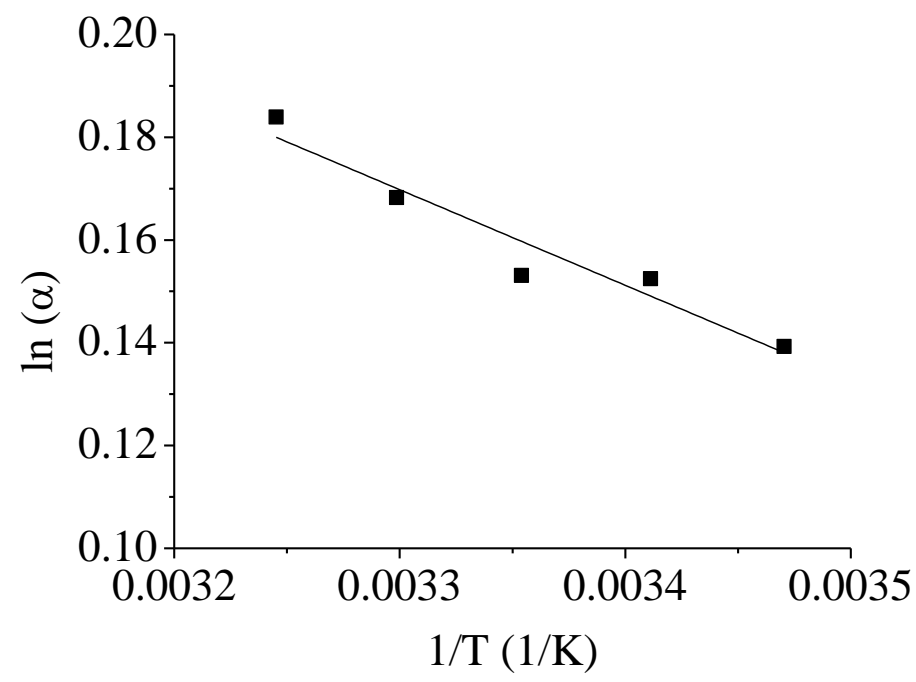

Figure 4 - Van't Hoff graphical in function of selectivity and temperature.

Table 2 - Thermodynamic parameters of the separation of racemic ibuprofen from Figure 4 .

\begin{tabular}{cccc}
\hline$\Delta \Delta H^{0}(\mathrm{~J} / \mathrm{mol})$ & $\Delta \Delta S^{0}(\mathrm{~J} / \mathrm{K} \mathrm{mol})$ & $\mathrm{R}^{2}$ & $T_{\text {iso }}(\mathrm{K})$ \\
\hline 1546.88 & 6.52 & 0.936 & 237.81
\end{tabular}

\section{CONCLUSIONS}

The results obtained for the separation of racemic ibuprofen in columns packed with cellulose tris (3,5-dimethylphenylcarbamate) demonstrated a phenomenon of endothermic physisorption. The total porosity and ratio phase was determined. As expected, the R-(-)ibuprofen binds more energetically CSP and S-(+)-ibuprofen has a lower degree of freedom. With this work is possible conclude that the isoenantioselective temperature was below the working temperature. At higher temperature the separation is favored. Besides it, the enthalpy and mainly entropy influenced the phenomenon of adsorption in the temperature range studied.

\section{Symbols}

$\Delta G^{0}=$ standard Gibbs energy $(\mathrm{J} / \mathrm{mol})$

$\Delta H^{0}=$ standard enthalpy $(\mathrm{J} / \mathrm{mol})$

$\Delta S^{0}=$ standard entropy $(\mathrm{J} / \mathrm{K} \mathrm{mol})$

$\Delta S^{*}=$ standard entropy change under the influence of phase ratio $(\mathrm{J} / \mathrm{K} \mathrm{mol})$

$\Delta \Delta G^{0}=$ standard Gibbs energy between compound more and less retained $(\mathrm{J} / \mathrm{mol})$ 
$\Delta \Delta H^{0}=$ standard enthalpy energy between compound more and less retained $(\mathrm{J} / \mathrm{mol})$

$\Delta \Delta S^{0}=$ standard entropy energy between compound more and less retained $(\mathrm{J} / \mathrm{mol})$

$k=$ retention factor

$L=$ column length $(\mathrm{cm})$

$R=$ universal gas constant $(8.3144 \mathrm{~J} / \mathrm{mol} \mathrm{K})$

$t_{0}=$ dead time of the column (min)

$t_{R}=$ retention time plus dead time (min)

$t_{R}^{\prime}=$ retention time $(\mathrm{min})$

$T=$ absolute temperature $(\mathrm{K})$

$T_{\text {iso }}=$ isoenantioselective temperature $(\mathrm{K})$

$v=$ superficial velocity $(\mathrm{cm} / \mathrm{min})$

\section{Greek letters}

$\alpha=$ selectivity

$\varepsilon=$ total porosity

$\phi=$ phase ratio

\section{REFERENCES}

ASNIN, L.; KACZMARSKI, K.; FELINGER, A.; GRITTI, F.; GUIOCHON, G. Adsorption of the enantiomers of 3-chloro-1-phenyl-propanol on silica-bonded chiral quinidine carbamate. J. Chromatogr. A, v. 1101, n. 1, p. 158-170, 2006.

CHEN, C., S.; SHIEH, W., R.; LU, P., H.; HARRIMAN, S.; CHEN, C., Y. Metabolic stereoisomeric inversion of ibuprofen in mammals. BBA-Protein Struct. M., v. 1078, n. 3, p. 411-417, 1991.

COYM, J. Evaluation of ternary mobile phases for reversed-phase liquid chromatography: Effect of composition on retention mechanism. J. Chromatogr. A, v. 1217, n. 38, p. 5957-5964, 2010.

CREMASCO, M. A.; HRITZKO, B. J.; XIE, Y.; WANG, N. H. L. Parameters estimation for amino acids adsorption in a fixed bed by moment analysis. Braz. J. Chem. Eng., v. 18, n. 2, p. 181-194, 2001.

FERRARI, W. M.; CREMASCO, M. A. Study of the separation conditions of the racemic ibuprofen on high performance liquid chromatography. Anais Eletrônicos do $10^{\circ}$ Encontro Brasileiro sobre Adsorção - EBA 2014

JANDERA, P.; COLIN, H.; GUIOCHON, G. Interaction indexes for prediction of retention in reversed-phase liquid chromatography. Anal. Chem., v. 54, n. 3, p. 435-441, 1982. 
LÄMMERHOFER, M. Chiral recognition by enantioselective liquid chromatography: mechanisms and modern chiral stationary phases. J. Chromatogr. A, v. 1217, n. 6, p. 814-856, 2010.

MIHLBACHLER, K.; KACZMARSKI, K.; SEIDEL-MORGENSTERN, A; GUIOCHON, G. Measurement and modeling of the equilibrium behavior of the Tröger's base enantiomers on an amylose-based chiral stationary phase. J. Chromatogr. A, v. 955, n. 1, p. 35-52, 2002.

MOREIRA, J., V.; NASCIMENTO, A., C.; CREMASCO, M., A. Determination of isoselective temperature and selectivity for the products of piperonal organic synthesis from Piper hispidinervum c. dc by high-performance liquid chromatography on c18 stationary phase VII CBTermo, 2013.

NASCIMENTO, A. C.; PERNA, R. F.; CREMASCO, M. A.; SANTANA, C. C. Enantioseparation of Secnidazole by High-Performance Liquid Chromatography using Amylose-based Stationary Phase. Adsorpt. Sci. Technol., 30 (2012), 739-750.

OLIVEIRA, C., E., L; CREMASCO, M., A. Estudo termodinâmico da retenção cromatrográfica de uma mistura binária carvacrol-timol utilizando a técnica de cromatografia de alta eficiência. VII CBTermo, 2013.

PALMA, C.; DI PAOLA, R.; PERROTTA, C.; MAZZON, E.; CATTANEO, D.; TRABUCCHI, E.; CUZZOCREA, S.; CLEMENTI, E. Ibuprofen-arginine generates nitric oxide and has enhanced anti-inflammatory effects. Pharmacol. Res., v. 60, n. 4, p. 221-228, 2009.

PÉTER, A.; TÖRÖK, G.; ARMSTRONG, D. W.; TÓTH, G.; TOURWÉ, D. Effect of temperature on retention of enantiomers of $\beta$-methyl amino acids on a teicoplanin chiral stationary phase. J. Chromatogr. A, v. 828, n. 1, p. 177-190, 1998.

SCHNEIDER, P.; SMITH, J. M. Adsorption rate constants from chromatography. AlChE J., v.14, n. 5, p. 762-771, 1968.

SCHULTE, M.; EPPING, A. Fundamentals and General Terminology in SCHMIDTTRAUB, H. Preparative Chromatography of Fine Chemicals and Pharmaceutical Agents. Weinheim: Wiley-VCH, 2005.

VALDERRAMA, P.; POPPI, R. J. Second order standard addition method and fluorescence spectroscopy in the quantification of ibuprofen enantiomers in biological fluids. Chemometr. Intell. Lab., v. 106, n. 2, p. 160-165, 2011.

YOON, J., S.; YOON, D.; OH, J.; KEUN, Y., L.; LEE, H, S.; KOH, Y., Y.; JIN, T., K.; KANG, H., J.; LEE, J., S. The effects and safety of dexibuprofen compared with ibuprofen in febrile children caused by upper respiratory tract infection. Brit. J. Clin. Pharmaco., v. 66, n. 6, p. 854-860, 2008. 